\title{
O DISCURSO FUNDADOR E A EDUCAÇÃO DE JOVENS E ADULTOS: UM MOVIMENTO SOCIA̧L NECESSÁRIO NO BRASIL
}

\author{
MARILDA DE CASTRO LARAIA; ANDREA SILVA DOMINGUES
}

Faculdade de Filosofia, Ciências e Letras Eugênio Pacelli - Universidade do Vale do Sapucaí - Av. Pref. Tuany Toledo, 470 - 37550-000 - Pouso Alegre - MG - Brasil

marildalaraia@gmail.com ; andrea.domingues@gmail.com

\begin{abstract}
Resumo. O presente artigo teve como objetivo entender os diferentes sentidos discursivos produzidos na prática pedagógica e nos livros didáticos do Ensino de Jovens e Adultos (EJA) na cidade de Pouso Alegre-MG; bem como o sentido dessa prática e desses materiais para os educandos. Teórica e metodologicamente, esta pesquisa se filia à Análise de Discurso francesa e aos estudos realizados por Eni P. Orlandi. Selecionamos, para esta análise, o livro didático "É bom aprender", editado no ano de 2009, que atende as exigências da Resolução nº. 51, de 16/09/2009. Além de estarmos atentos aos sentidos produzidos por tal livro didático, também realizamos entrevistas - iniciativa na qual empregamos a metodologia da História Oral - com um sujeito-aluno do Centro Municipal de Educação de Jovens e Adultos, buscando entender, por meio do instrumental teórico da Análise do Discurso, as formas discursivas que emergem do processo de ensino-aprendizagem e seus sentidos para os educandos inscritos no EJA.
\end{abstract}

Palavras-chave: ensino; EJA; memória; linguagem.

\begin{abstract}
This article aimed to understand the production of different discursive meanings in pedagogical practice with textbooks designed for Youth and Adult Education (EJA) in the city of Pouso Alegre-MG, as well as the meaning of this practice and these materials for learners. Theoretically and methodologically, this research is affiliated to the French Discourse Analysis and to studies established by Eni Puccinelli Orlandi. We have selected for this analysis the textbook "É bom aprender", published in the year of 2009, which meets the requirements of resolution 51 , from 16/09/2009. In addition to regard the meanings produced by such textbook, we also performed interviews - initiative in which we have employed the methodology of Oral History - with a fellow-pupil of the Municipal Center for Adult and Youth Education, seeking to understand the configuration of discursive forms that emerge from the teaching-learning process and its meaning for learners who are enrolled at EJA.
\end{abstract}

Keywords: education; EJA; memory; language.

\section{Apresentação}

Inserido na perspectiva das ciências da linguagem, este trabalho propõe-se a refletir sobre o material didático destinado à Educação de Jovens e Adultos (EJA) e, principalmente, sobre o processo de produção de sentidos engendrado a partir desse material. Para isso, será realizada uma análise da capa, do prefácio e de dois exercícios 
do livro didático usado por alunos da EJA. Além disso, este artigo pretende analisar o discurso do aluno que frequenta a EJA, aqui ilustrado com recortes de uma narrativa oral produzida por um aluno do Centro Municipal de Educação de Jovens e Adultos (CMEJA). localizado em Pouso Alegre, cidade do sul do Estado de Minas Gerais. É com base nesse material de análise que buscamos compreender as formas discursivas que emergem do processo de ensino-aprendizagem, bem como os sentidos que elas produzem nos e para os educandos da EJA. Em outras palavras, desenvolvemos um estudo que toma, como ponto de partida, duas questões importantes no processo de ensino-aprendizagem, a saber: o instrumento (livro didático) e o aluno, investigando o percurso significante e seus efeitos de sentidos a partir de cada um desses elementos.

O desenvolvimento de políticas de formação de pessoas jovens e adultas, que atenda a esse novo paradigma de educação continuada, é tema polêmico, mas permite que se identifiquem algumas indicações mais ou menos consensuais.

A primeira delas relaciona-se à iniciativa que os indivíduos têm de traçar, com autonomia, suas próprias biografias formativas. A segunda indicação recomenda modificar as práticas de planejamento das agências formadoras, levando-as a realizar um "giro" da oferta para a demanda, ou seja, a deixar de conceber a oferta educativa a partir de padrões únicos (quase sempre referidos aos parâmetros da educação escolar de crianças e adolescentes), passando a concebê-la a partir da diversidade de demandas concretas dos diferentes segmentos sociais. A terceira implica reconhecer que não apenas a escola, mas muitas outras instituições e espaços sociais têm potencial formativo - o trabalho e as empresas, os meios de comunicação, as organizações comunitárias, os equipamentos públicos de saúde, cultura, esportes e lazer etc., aproveitando ao máximo esse potencial e reconhecendo a legitimidade do conhecimento adquirido por meios extraescolares. (DI PIERRO; JÓIA; RIBEIRO, 2001, p. 70-71)

Superar a concepção compensatória de educação de pessoas adultas não implica, porém, negar que há desigualdades educativas a serem enfrentadas. A tendência histórica à ampliação e ao alongamento da educação básica vem produzindo aquilo que os sociólogos da educação denominam "efeito desnivelador" cada vez que se amplia a escolaridade mínima obrigatória, um novo contingente de jovens e adultos fica com uma escolaridade inferior àquela a que todo cidadão tem direito (FLECHA GARCIA, 1996).

Ainda como nos alerta Di Pierro, Jóia e Ribeiro (2001), "assegurar essa escolaridade mínima comum é responsabilidade da qual o poder público não pode esquivar-se, ainda que possa contar com a colaboração da sociedade civil organizada para efetivá-la".

Isso não significa que a educação básica de jovens e adultos deva reproduzir as formas de organização, currículos, métodos e materiais da educação básica infantojuvenil. No entanto, a experiência internacional recomenda flexibilizar currículos, meios e formas de atendimento, integrando as dimensões de educação geral e profissional, reconhecendo processos de aprendizagem informais e formais, combinando meios de ensino presenciais e a distância, de modo que os indivíduos possam obter novas aprendizagens e a certificação correspondente mediante diferentes trajetórias formativas. 
Analisar as entrevistas orais do sujeito-aluno da EJA possibilitou-nos observar como a sociedade se significa e como o aluno da EJA se relaciona com a discursividade, uma vez que o gesto de aprender é praticado por esse sujeito à medida que ele desabrocha para a leitura e para a escrita. Esses sujeitos se identificam nesse processo, no qual operam as condições de produção que afetam o modo como se constroem diferentes posiçõessujeito, a saber: sujeito-educador e sujeito-educando da EJA. Nesse trilhar, é importante a compreensão do discurso, pois os alunos da EJA, em sua maioria, são trabalhadores que tiveram pouco tempo de permanência no sistema escolar. Isso é perceptível em sua formação discursiva, a qual denota a ausência de uma relação com a escola como instituição e com o professor como sendo aquele que ensina. Melhor dizendo, o sujeitoaluno da EJA possui um discurso próprio advindo de sua vivência, ou seja, um discurso adquirido da escola da vida, segundo Paulo Freire (1996).

Neste estudo, trabalhamos com a memória discursiva, entendida como interdiscurso, pois "alguma coisa fala antes, em outro lugar e independente" (PÊCHEUX, 1991, p. 142). Ela faz parte de um processo histórico, no qual há uma linguagem em funcionamento, em disputa, que se apropria da memória e que se manifesta sob a forma de discursos distintos. Nesse processo de se constituir aprendiz da EJA, as diferentes memórias são reclamadas, havendo o político em jogo e a divisão dos sentidos.

\section{O livro didático}

No universo que compõe a escola, vários elementos se fazem presentes e, dentre eles, está o livro didático, constituindo-se como um instrumento pedagógico que, por vezes, torna-se alvo da crítica de estudiosos que entendem que o livro didático não pode ser o único material de ensino. Mas o que é, então, o livro didático? Como podemos defini-lo? Segundo Bittencourt (2004),

Diversas pesquisas têm revelado que [os livros didáticos] são um instrumento a serviço da ideologia e da perpetuação de um "ensino tradicional" [...]. Constituiu também um suporte de conhecimentos escolares propostos pelos currículos educacionais. Essa característica faz que o Estado esteja sempre presente na existência do livro didático: interfere indiretamente na elaboração dos conteúdos escolares veiculados por ele e posteriormente estabelece critérios para avaliá-lo, seguindo, na maior parte das vezes, os pressupostos dos currículos escolares institucionais (pp. 300-301).

Percebemos a necessidade do uso do livro didático na sala de aula como um instrumento pedagógico para a prática docente. Vale ressaltar ainda que, muitas vezes, o livro é confundido como material norteador dessa mesma prática e que, em seus conteúdos, nos é possível notar a presença da ideologia do Estado, responsável por distribuir, gratuitamente, os livros às escolas e aos alunos. Devemos ressaltar que, neste estudo, não buscamos estereotipar o livro didático como herói ou vilão, mas sim refletir sobre ele como um objeto de análise impregnado de sentidos, ideologias e memórias. 
Em se tratando, especificamente, do livro didático adotado para o ensino da EJA, verificamos uma grande conquista, devido ao fato de que, no período anterior ao ano de 2009, usava-se, na EJA, o mesmo material didático utilizado no Ensino Fundamental regular, ou seja, adotava-se, para ensinar o adulto, um material com a linguagem voltada ao ensino de crianças e de adolescentes. A partir de 2010, mudanças significativas foram observadas em relação a essa questão, já que, a partir desse ano, a EJA passou a empregar material didático específico às suas necessidades e às necessidades de seu público-alvo.

De fato, essa adequação parece-nos muito significativa e fornece dados importantes para a pesquisa que desenvolvemos porque é inegável a existência de uma grande diferença entre o processo de ensino-aprendizagem de uma criança e o de um adulto. Cavalcanti (1999, p. 19) assinala que:

a idade adulta traz a independência. O indivíduo acumula experiências de vida, aprende com os próprios erros, apercebe-se daquilo que não sabe e o quanto este desconhecimento faz-lhe falta. Escolhe uma namorada ou esposa, escolhe uma profissão e analisa criticamente cada informação que recebe, classificando-a como útil ou inútil. Esta evolução, tão gritante quando descrita nestes termos, infelizmente é ignorada pelos sistemas tradicionais de ensino. Nossas escolas, nossas universidades tentam ainda ensinar a adultos com as mesmas técnicas didáticas usadas nos colégios primários ou secundários. A mesma pedagogia é usada em crianças e adultos, embora a própria origem da palavra se refira à educação e ensino das crianças (do grego paidós $=$ criança).

Diferentemente das crianças, que dependem sempre de um adulto e que se submetem a tal dependência em idade escolar - assim como se submetem à autoridade do professor -, o aluno adulto insere-se no contexto escolar com certa independência. Essa distinção deve também ser considerada no processo de ensino-aprendizagem, apesar de ter sido, historicamente, ignorada pelas escolas que comumente adotavam a mesma pedagogia para crianças e adultos. A essa educação específica para jovens e adultos, Cavalcanti (1999) propõe o termo "andragogia"1.

Diante desse contexto, emerge a necessidade de se elaborar um material pedagógico específico para os alunos da EJA. Sabedor dessa necessidade, o Ministério da Educação (MEC), por meio do Fundo Nacional de Desenvolvimento da Educação (FNDE), promulga a Resolução $\mathrm{n}^{\circ}$. 51, de 16 de setembro de 2009,

[c]onsiderando a necessidade de estabelecer um programa nacional de distribuição de livro didático adequado ao público da educação de jovens, adultos e idosos, como um recurso básico, no processo de ensino e aprendizagem. (BRASIL, 2009)

Nota-se, no discurso legislador, o reconhecimento de tal necessidade já percebida anteriormente pelos profissionais da educação envolvidos no processo de ensinoaprendizagem dos sujeitos alunos da EJA. Aqui são estabelecidas a elaboração e a

\footnotetext{
${ }^{1}$ Andragogia é a arte ou ciência de orientar adultos a aprender, segundo a definição creditada a Malcolm Knowles, na década de 1970. O termo remete a um conceito de educação voltada para o adulto, em contraposição à pedagogia, que se refere à educação de crianças.
} 
distribuição de material didático que, para atender à realidade do aluno da EJA, deve se apresentar com linguagem própria, constituindo-se como um instrumento que auxilie na formação desse sujeito-aluno, conforme os moldes que conduzem os interesses do Estado, de acordo com a Lei de Diretrizes e Bases da Educação Nacional nº. 9394/96:
Seção V
Da Educação de Jovens e Adultos
$[\ldots]$
Art. 37. A educação de jovens e adultos será destinada àqueles que não tiveram acesso ou continuidade de estudos no ensino fundamental e médio na idade própria.
$\S 1^{\circ}$. Os sistemas de ensino assegurarão gratuitamente aos jovens e aos adultos, que não puderam efetuar os estudos na idade regular, oportunidades educacionais apropriadas, consideradas as características do alunado, seus interesses, condições de vida e de trabalho, mediante cursos e exames.
$\S 2^{\circ}$. O Poder Público viabilizará e estimulará o acesso e a permanência do trabalhador na escola, mediante ações integradas e complementares entre si. (BRASIL, 1996).

A partir do direcionamento exigido pela lei, a qual enuncia a viabilização do acesso e o estímulo, ao aluno da EJA, de permanecer dentro do processo ensinoaprendizagem institucionalizado, podemos observar que um dos elementos que complementa essa inserção é o livro didático capaz de produzir sentidos a esses estudantes.

Um desses materiais previstos pela Resolução n ${ }^{\circ}$. 51/2009 é o livro didático da coleção "É bom aprender", publicado pela editora FTD em 2009. Esse livro constitui o corpus de análise deste estudo, que intenta problematizar e compreender o processo de produção de sentidos do sujeito-aluno da EJA. Na próxima seção, realizaremos nosso exercício analítico.

\section{Olhares analíticos para o material didático da EJA}

O livro didático adotado para análise é distribuído gratuitamente aos alunos pelo Programa Nacional do Livro Didático para Educação de Jovens e Adultos (PNLD - EJA). O primeiro livro a ser investigado corresponde ao volume 1 - "Multidisciplinar" -, primeiro segmento do Ensino Fundamental da coleção “É bom aprender". Observamos o componente curricular Língua Portuguesa. 


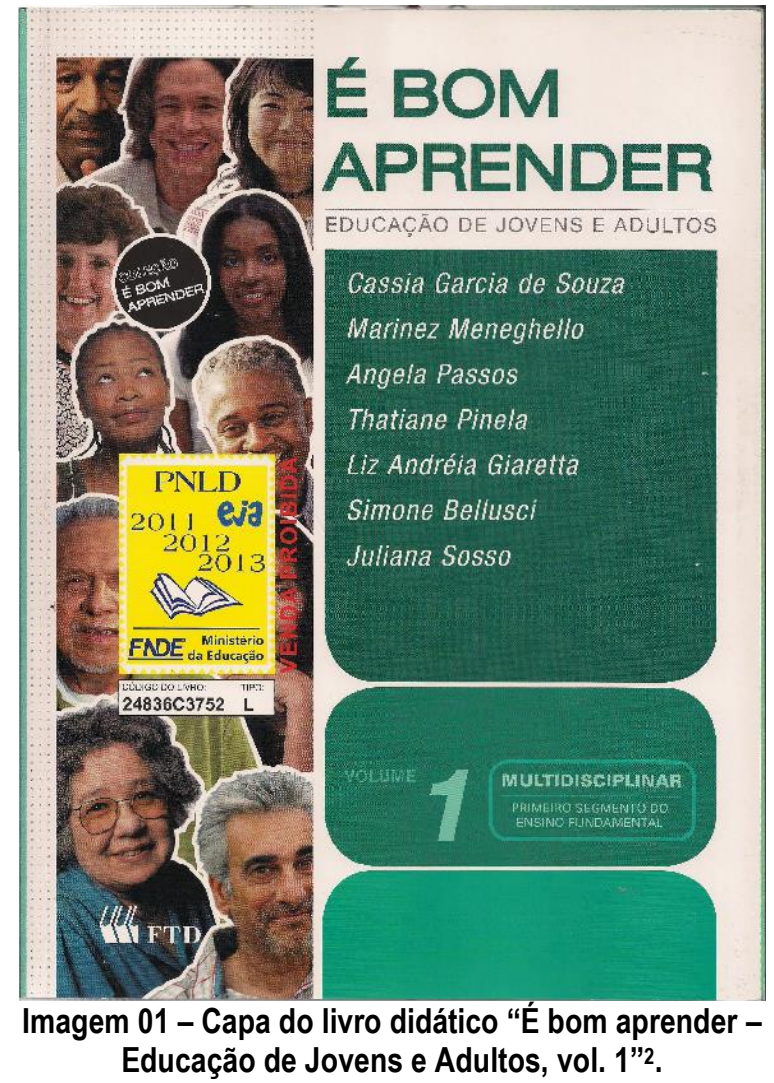

A capa do livro didático analisado traz em destaque, na parte superior esquerda, o seguinte enunciado: “É BOM APRENDER". Aprender é verbo regular transitivo, ou seja, exige um complemento. Daí se abrem possibilidades para diferentes formações discursivas como:

\section{"É BOM APRENDER (?)"; \\ "É BOM APRENDER (!)"; \\ "É BOM APRENDER (...)".}

Ao analisar as formações discursivas apresentadas, abre-se espaço para o questionamento do que se deve aprender, para que se deve aprender e se, de fato, é bom aprender. A investigação nos permite realizar uma reflexão sobre como somos significados e nos significamos pelo discurso oficializado pelo sistema de ensino através do Estado.

A questão da Educação de Jovens e Adultos (EJA) aproxima-nos de várias dimensões - como a política, a social e a cultural - e, embasados na problemática educacional da atualidade, buscamos compreender a complexidade do contexto em que se insere o aluno da EJA por meio do seguinte questionamento: quais são os sentidos que a formação da EJA produz para esses sujeitos?

\footnotetext{
${ }^{2}$ SOUZA et al. É bom aprender: língua portuguesa, matemática, ciências, história e artes, volume 1: Educação de Jovens e Adultos - EJA, São Paulo: FTD, 2009.
} 
O desenvolvimento desta pesquisa se constituiu em um importante exercício, a partir do qual corroboramos que não há discurso sem sujeito nem sujeito sem ideologia (PÊCHEUX, 1975). No decorrer da construção da escrita deste texto, recorremos a diversas teorias que foram fundamentais à compreensão de como pensamos e agimos como analistas de discurso. A partir das leituras de Eni Orlandi (2005), pudemos problematizar, por meio da $\mathrm{AD}$, nossa maneira de ler e de pensar sobre o que falamos e ouvimos das diferentes manifestações da linguagem, sem deixarmos de nos comprometer com os sentidos e com a dimensão política.

No que se refere à aprendizagem, pressupomos que o sujeito adquirirá conhecimentos que lhe possibilitarão transitar em diferentes ambientes, constituindo-se sujeito ativo e participativo, capaz de uma maior reflexão de seus atos e de seus dizeres. $\mathrm{O}$ ato de aprender produz sentidos de autonomia, discernimento e criticidade, que possibilitam que o sujeito se sinta mais autônomo e mais crítico em relação ao mundo em que se encontra inserido e seus diferentes ambientes (como no ambiente de trabalho).

Quando a aprendizagem está atrelada ao conhecimento que se estabelece ao ensino da EJA, percebemos vários sentidos. Na enunciação "É BOM APRENDER", observa-se o funcionamento de uma formação discursiva amparada em certas ideologias, como a autovalorização do sujeito-aluno, a esperança de ascensão social, novas oportunidades de trabalho e, finalmente, a constituição da individualização do sujeito, uma vez que há um sentido positivo para o processo de ensino-aprendizagem que exemplifica a afirmação de Orlandi (2004), para quem "o conhecimento [é] considerado como modo de integração social” (pp. 152-153).

Sabemos que "a linguagem serve para comunicar e para não comunicar. As relações de linguagem são relações de sujeitos de sentidos e seus efeitos são múltiplos e variados. Daí a definição de discurso: o discurso é efeito de sentidos entre locutores" (ORLANDI, 2005, p. 21). Assim, deparamo-nos com diferentes sentidos produzidos pelo enunciado "É BOM APRENDER", o qual demonstra intencionalidade, evidenciando que há benefícios que se vinculam ao ato de aprender. Isso se mostra de forma diferenciada para o aluno da EJA, que possui uma trajetória específica distante do espaço escolar.

Em nossa análise do livro didático, chamou-nos a atenção o prefácio, onde encontramos uma mensagem dos autores aos sujeitos-alunos que farão uso do livro.

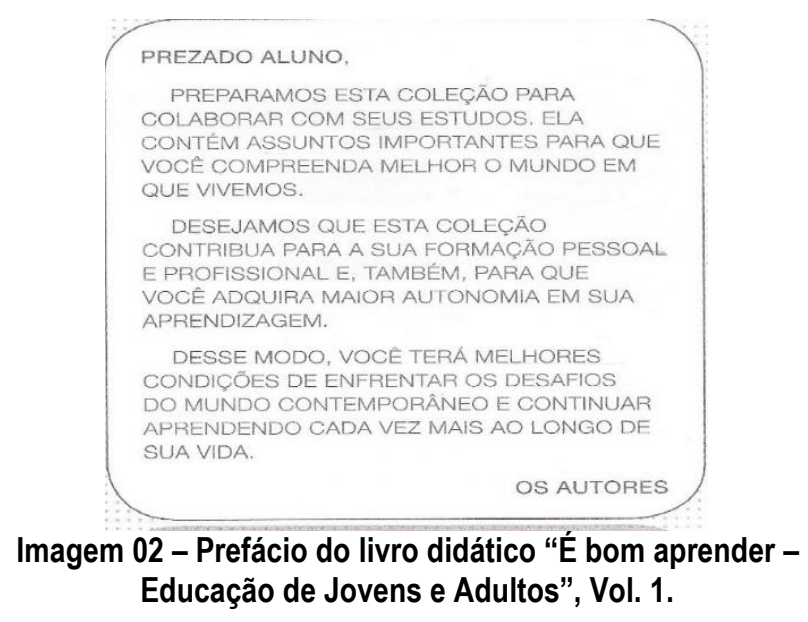


Tomemos alguns fragmentos desse escrito para examiná-los à luz da Análise do Discurso. Ao apontar o texto, devemos entendê-lo como uma unidade de sentido entre interlocutores que configura um corpus que deixa de ser texto para ser objeto discursivo, já que se apresenta como sendo o lugar mais adequado para se observar o fenômeno da linguagem. O texto abre-se enquanto objeto simbólico para diferentes possibilidades de leituras, ou seja, acontece aí um processo de textualização do discurso que, na maioria das vezes, apresenta-se com "falhas" (ORLANDI, 2008 apud LARAIA, 2013).

Uma letra 'O', escrita em uma porta, ao lado de outra com a letra 'A', indicando-nos os banheiros masculino e feminino, é um texto pois é uma unidade de sentido naquela situação. E isso refere, em nossa memória, o fato de que em nossa sociedade, em nossa história, a distinção masculino/feminino é significativa e praticada socialmente (ORLANDI, 2005, p. 69).

Conforme nos alerta a autora, o discurso é uma disseminação de textos, sendo o texto uma dispersão do sujeito. O discurso não se fecha, ele é um processo em curso; não é um conjunto de textos, mas sim uma prática.

A partir desta pesquisa, que visa a discutir os diferentes sentidos presentes no livro didático que se destina à educação exclusiva de jovens e adultos, buscamos perceber os diversos movimentos dos dizeres que constituem o discurso dos autores do livro em questão, quando se referem ao aluno, à organização escolar, entre outros. Procuramos evidenciar as diferentes formas de se referir ao sujeito, o qual fará uso desse material de estudo.

Para Pêcheux (1990, p. 26), "o discurso permite dizer algo além do texto mesmo, com a condição de que o texto seja de certo modo realizado; o discurso deve ser tratado como práticas descontínuas que se cruzam por vezes, mas que também se ignoram ou se excluem".

Podemos perceber como é visto o texto: não como algo em si, que somente se configura com vários enunciados juntamente tecidos, mas sim como uma materialidade que possibilita uma análise mais atenta, não somente da questão gramatical, mas de todo um processo de produção que perpassa as condições de produção, a ideologia, a memória discursiva e o sujeito. $\mathrm{O}$ texto consiste em um lugar regido e marcado por conflitos, em que vários movimentos o conduzem, tais como rupturas, silêncios e repetições.

Observemos com mais atenção estes fragmentos:

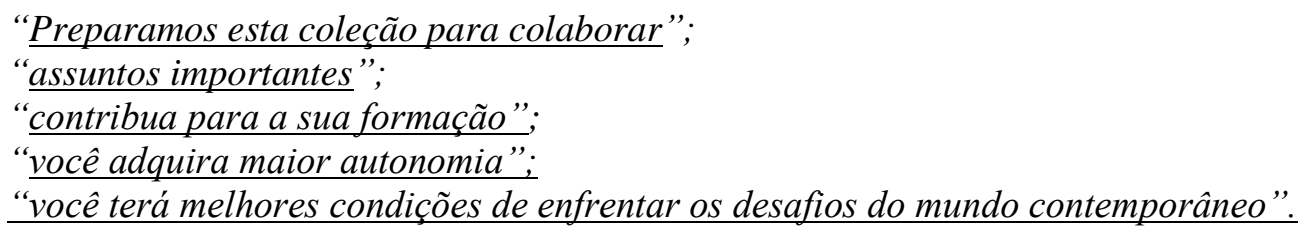

Orlandi (2010) diz que os sujeitos são seres simbólicos e históricos e, por isso, necessitam dos sentidos para viverem. Os fatos reclamam sentidos e tais sentidos compõem a história. Porém, os sentidos não se encontram na sua literalidade, ou seja, na 
essência das palavras. Sabemos que, para que a língua faça sentido, é necessário que ela se inscreva na história.

"Sujeito e sentido se constituem ao mesmo tempo. Ao significar, o sujeito está se significando" (ORLANDI, 2010, p. 11). Na dinâmica da construção do discurso, notamos a utilização daquilo que faz sentido para o sujeito, do que é depositado na memória, dos já ditos e esquecidos que, ao serem ouvidos novamente, constituirão novos sentidos e significados que se desdobrarão na significação do sujeito diante das condições de produção (LARAIA, 2013).

Podemos perceber isso claramente quando os autores dizem "assuntos importantes" e "contribua para a sua formação". A partir desse recorte, nos é possível compreender que, alguma vez e em algum lugar, esse sujeito-aluno da EJA já ouviu alguém lhe dizer que é na escola que se aprende e que são os conteúdos do livro didático que são os mais importantes para a sua aprendizagem.

O sujeito não constitui a fonte incondicional do sentido, do significado, ou seja, ele não é origem porque é constituído por dizeres de outros sujeitos (LARAIA, 2013). Notamos que o sujeito é resultado da influência de vozes diversas, isto é, da relação do socioideológico.

Quando os autores assinalam: "você terá melhores condições de enfrentar os desafios do mundo contemporâneo e continuar aprendendo", é notório que toda a ideologia do Estado está infiltrada nos dizeres dos autores que elaboraram o material para ser vendido ao Estado e, posteriormente, distribuído gratuitamente aos alunos das escolas públicas. Quem garante que esse sujeito-aluno terá mesmo melhores condições para enfrentar os desafios desse mundo contemporâneo? Que mundo é esse que os autores desenham para esses alunos? Certamente um mundo capitalista, no qual quanto mais se produz, melhor é para todos. Mas será que realmente esses autores estão preocupados com o eu desse sujeito-aluno?

$\mathrm{Na} \mathrm{AD}$, uma questão fundamental é a historicidade, pois, quando se fala em sujeito, devemos imediatamente considerar a relação língua/sujeito/história. Da mesma forma, quando se fala em sociedade, devemos considerá-la em seu determinado contexto histórico (ORLANDI, 2010). O sujeito está entrelaçado à história e, através dela, constitui sua memória discursiva. É com base nessa memória discursiva que ele será capaz de formular seus dizeres, nos quais podem ser encontradas rupturas, deslocamentos, equívocos, entre outros, dependendo do momento político-sócio-histórico em que ele se encontra (LARAIA, 2013).

O fato de imaginarmos que somos sempre sujeitos nos subtrai a ideia de que o indivíduo é interpelado em sujeito pela ideologia. A partir dessa delimitação, notamos as evidências que proporcionam o assujeitamento, que se baseia na ação de significar e, automaticamente, significar-se.

$\mathrm{Na}$ análise, buscamos também identificar os sentidos que se inscrevem nas entrevistas realizadas com os sujeitos-alunos da EJA. Procuramos perceber, com nossas análises, as diversas posições-sujeito adotadas por esses alunos que configuram sentidos em sua vivência. 
Examinemos alguns recortes da entrevista oral ${ }^{3}$ concedida pela Senhora L.S.N., de 37 anos, moradora do Bairro Jardim Paraíso, promotora de vendas, aluna da EJA do quarto ano do Ensino Fundamental:

Recorte 01:

Entrevistadora: Primeira coisa, por que você veio estudar na EJA?

Entrevistada: Ah, porque eu sabia muito pouco, entendeu? E eu precisava do estudo. Porque eu tenho três filhos, né? Porque a gente precisa, a gente precisa ensinar eles também, né? Precisa manda eles pra escola pelo menos a gente vindo, né? Só que na época eu não sabia que tinha aqui o CEMEJA, só tinha a... só sabia que tinha o CESU, e lá se faz, tudo bem, ensina muito bem, também, mais é mais difícil, porque o professor vai mais pouco, né? O professor tá todo dia presente, é difícil? [Aqui ela se refere ao CEMEJA] É! Você tem que vim todo o dia, a gente que tem fio, tem casa, tem que deixa os fios, né? É difícil. Tem dia que tem que ter coragem, mais como a gente vê as pessoas de mais idade que tá vindo todo o dia, tem bastante senhora, eles dão animação pra gente, vindo, dão força, entendeu? Mais é difícil. Entendeu?

A entrevistada, nosso sujeito-aluno neste momento, mostra de imediato que sente necessidade, em sua vida, do "saber", quando ela diz "eu sabia pouco, entendeu?"

Nota-se também a tomada de consciência diante da realidade na qual está inserida e a qual abrange os filhos que já frequentam a escola: "porque eu tenho três filhos, né? Porque a gente precisa, a gente precisa ensinar eles também, né?" Com esse dizer, deparamo-nos com o sujeito-mãe antes de se tornar sujeito-aluno, quando ela demonstra a preocupação e a necessidade de ter que ensiná-los. Nesse momento, esse sujeito reconhece que não tem o conhecimento necessário para ensinar seus filhos e, portanto, é indispensável que se assujeite à condição de aluno.

Compreendemos, assim, um deslocamento da posição sujeito-mãe para sujeitoaluno, devido ao fato de ela, ideologicamente, achar que é mais importante, nesse momento, sua formação como sujeito-mãe. Com tal movimento, ela assume a posição de sujeito-aluno com vistas a desempenhar bem o papel de sujeito-mãe, dando sentido ao seu ingresso na escola.

Orlandi (2005) nos diz que o sentido não existe em si, mas que é determinado pelas posições ideológicas. Essa posição ideológica em que ela se encontra nesse momento é a posição sujeito-mãe, que a impeliu a se assujeitar ao sistema escolar.

\footnotetext{
${ }^{3}$ Seguimos, para a constituição do corpus referente às entrevistas que serão analisadas, a metodologia ligada à prática da História Oral. Optamos, no ato da transcrição, por manter a originalidade da fala dos nossos entrevistados e também por não expor a identidade deles, que foi substituída pelas iniciais dos nomes. Todas as entrevistas foram autorizadas por meio da carta de cessão.
} 
A entrevistada faz referência ao CESU (Centro de Ensino Supletivo), que corresponde a um sistema de ensino diferente da EJA, no qual o aluno estuda em casa e, quando sente necessidade, procura o professor que, em sistema de plantão, o atende no CESU. Por isso, a entrevistada diz que o CESU lhe parece ser mais difícil. Nota-se aí que a entrevistada tem necessidade da presença constante do sujeito-professor no processo de ensino-aprendizagem. Qual seria o motivo que a leva a dizer que, com o professor presente, torna-se mais fácil para ela aprender?

Compreendemos, em seus dizeres, a formação ideológica de que o professor sempre sabe mais e que é um sujeito capaz de conduzir, com mais segurança, o processo de ensino-aprendizagem. Quando ela afirma que é difícil estudar sem a presença do professor é porque demonstra não ter segurança. Não há a utilização da palavra "insegura", mas, de acordo com Orlandi (2005, p. 30), podemos perceber que:

\begin{abstract}
os dizeres não são, como dissemos, apenas mensagens a serem decodificadas. São efeitos de sentidos que são produzidos em condições determinadas e que estão de alguma forma presentes no modo como se diz, deixando vestígios que o analista de discurso tem de apreender. São pistas que ele aprende a seguir para compreender os sentidos aí produzidos, pondo em relação o dizer com sua exterioridade, suas condições de produção. Esses sentidos têm a ver com o que é dito ali, mas também em outros lugares, assim como com o que não é dito, e com o que poderia ser dito e não foi. Deste modo, as margens do dizer, do texto, também, fazem parte dele.
\end{abstract}

No entanto, a escolha da EJA deve-se ao fato da presença constante do professor. A escolha se pauta no já-dito que o professor é detentor de um grande saber e que esse mesmo professor vai lhe transmitir esse saber. Quando a entrevistada se manifesta discursivamente, referindo-se ao fato de que, sem a presença do professor é mais difícil, confrontamo-nos com o efeito do já-dito, que, de acordo com Pêcheux (1997), corresponde a algo que fala, sempre, "antes, em outro lugar, independentemente" (p. 167).

Ao observar, no recorte 1, os dizeres "é difícil? É! Você tem que vim todo o dia, a gente que tem fio, tem casa, tem que deixa os fios, né?", percebemos, na narrativa, um sacrifício, uma escolha entre estar com os filhos e estar na escola, à qual se deve comparecer cotidianamente.

Segundo Pêcheux (1975), um acontecimento discursivo surge de uma estrutura. No exemplo tomado para estudo, encontramos o rompimento de uma estrutura já formada, uma vez que a entrevistada tem de deixar os afazeres de lado para se fazer presente à escola.

$\mathrm{Na}$ fala "Você tem que vim todo o dia", devemos ressaltar o fragmento "tem que", que assinala a obrigatoriedade imposta pelo sistema no que se refere à presença diária do aluno. Essa exigência consiste em uma maior dificuldade ao sujeito-aluno adulto que, na maioria das vezes, tem de trabalhar para se sustentar. A entrevistada sente todas essas dificuldades, porém não se deixa abater pelo desejo de adquirir o saber.

Continuamos com o recorte 1 da entrevista, do qual destacamos o seguinte fragmento: "Tem dia que tem que ter coragem, mais como a gente vê as pessoas de mais 
idade que tá vindo todo o dia, tem bastante senhora, eles dão animação pra gente, vindo, dão força, entendeu? Mais é difícil. Entendeu?"

A participante deixa entrever uma postura de resistência diante das dificuldades referentes aos estudos, pois, além de trabalhar como promotora de vendas, tem suas obrigações de trabalhadora do lar. O cansaço, muitas vezes, se torna manifesto, porém com a sociabilidade com outras alunas (também designadas como "senhoras"), a entrevistada vê-se motivada a continuar, uma vez que vê pessoas idosas almejando o início ou a continuação dos estudos.

Ao destacar em sua fala "dão força", a entrevistada se refere às alunas mais idosas como um exemplo de comportamento, atitude e dedicação aos estudos, mesmo que a formação educacional na EJA perpasse ou se desdobre em dificuldades.

Na sua construção discursiva, a entrevistada utiliza-se da expressão "entendeu?". Ela busca se fazer compreendida diante de sua fala, reforçando seu discurso por meio de uma interpelação/repetição interrogativa. Compreendemos, portanto, que a repetição é um evento, um acontecimento, porque, quando dizemos pela segunda vez, ou seja, quando insistimos, estamos pressupondo que o outro não entendeu algo. Quando repetimos, estamos dizendo aquela coisa primeira e mais alguma coisa.

Do ponto de vista da significação, não há uma relação direta do homem com o mundo, ou melhor, a relação do homem com o pensamento, com a linguagem e com o mundo não é direta assim como a relação entre linguagem e pensamento, e linguagem e mundo têm suas mediações. Daí a necessidade da noção de discurso para pensar estas relações mediadas. Mais ainda, é pelo discurso que melhor se compreende a relação entre linguagem/pensamento/mundo, porque o discurso é uma das instâncias materiais (concretas) desta relação. (ORLANDI, 2004, p. 12)

A partir da citação acima podemos dizer que a mediação existente (que é o discurso) entre a realidade do nosso sujeito-aluno e o mundo é sua relação com a linguagem, com seu cotidiano e com a escola, pois, dessa maneira, é possível analisar a problemática que constitui a presença de um adulto na EJA, frente às dificuldades e desafios que tal formação fomenta.

É importante destacar que esse sujeito-aluno vive sob o sistema de dominação, característico pelas diferenças entre as classes sociais e pela exploração de mão de obra capitalista. $\mathrm{O}$ contexto marca-se pela disputa de poder que levam a cabo diferentes atores sociais dentro do sistema educacional do Brasil, que ainda possui, em seu meio, um espaço de diferença, de exclusão, que classifica, fazendo com que o estudante tenha de viver em constante movimento de escolha e questionamentos do que e como aprender. 


\section{Os sentidos do ensino para a prática cotidiano}

O livro didático específico para os alunos da EJA deve ter seus conteúdos, como a Resolução $\mathrm{n}^{\circ} .51$ aponta, adequados aos alunos dessa modalidade de ensino, produzindo sentidos com sua vida, como veremos abaixo.

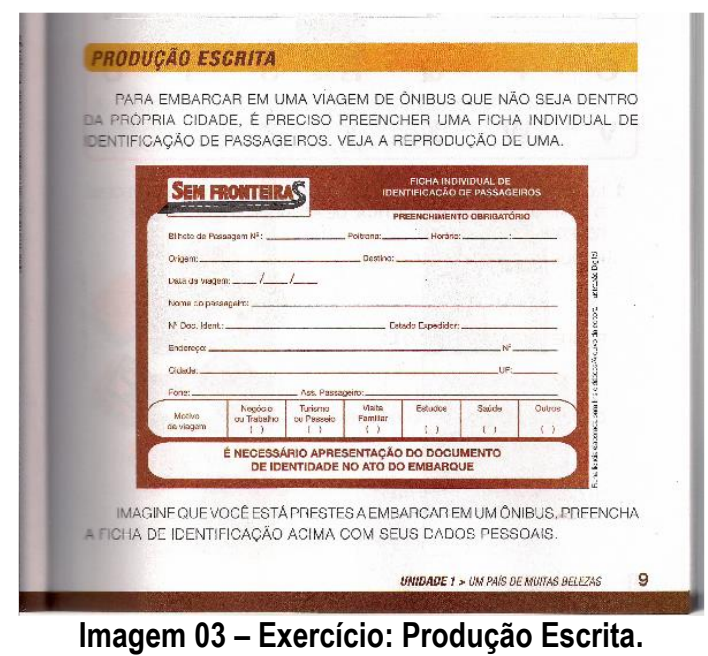

Logo às primeiras páginas do livro analisado, encontramos o exercício acima, que propõe que o aluno simule a necessidade de realizar uma viagem para outra cidade e, portanto, preencha a ficha de identificação para passageiros. A atividade mostra-se adequada às exigências da Resolução n. ${ }^{\circ} 51$ e, ao servir satisfatoriamente ao aluno da EJA, difere-se das atividades exploradas por um livro didático adotado pelo ensino regular.

O referido exercício da página 9 incentiva o aluno a construir uma produção escrita ligada diretamente a uma necessidade básica, que é seu direito de ir e vir. Esse exercício que possibilita a produção escrita se evidencia como um texto que vai ao encontro da observação de Orlandi (2003), para quem “o texto não é o lugar de informações - completas ou a serem preenchidas - mas é processo de significação, lugar de sentidos" (p. 196). Assim, entendemos que o ato de preencher uma ficha individual de identificação, para o sujeito-aluno da EJA, ultrapassa a simples ação de copiar seus dados, mas sim de uma significação que produz múltiplos sentidos, como, por exemplo, viajar sozinho sem depender de outra pessoa, iniciativa que oportuniza a conquista de maior autonomia diante de seus pares.

Aqui se instaura um processo de produção de sentidos, a partir do qual o sujeito aluno vê, nos exercícios propostos pelos materiais didáticos, que há não somente a promoção da aquisição de conhecimentos, mas também a utilização prática desse conhecimento em seu dia a dia.

Atentamos, também, ao enunciado "Sem Fronteiras", que se refere a uma empresa fictícia. Esse enunciado nos dá possibilidade de diferentes sentidos, que estabelecem sintonia com o anseio do aluno da EJA, que é estar na escola e adquirir conhecimentos, 
mesmo que básicos, que contribuam para uma vida mais fácil e autônoma. $\mathrm{O}$ aluno espera não necessitar mais de outras pessoas para preencher uma ficha de identificação porque essa dependência provoca-lhe constrangimentos. Ao se perceber capaz de preencher tal ficha, esse sujeito terá a sensação de ter adquirido a tão almejada autonomia. Nota-se, também, no exercício proposto, uma linguagem que faz parte do seu cotidiano marcado por obstáculos que o não saber estabelece.

Ao ouvirmos o posicionamento do aluno a respeito da EJA, deparamo-nos com as seguintes observações:

Recorte 2:

Entrevistadora: Que sentido a EJA está fazendo na sua vida?

Entrevistada: Ah eu acho que sim....

Entrevistadora: O que mudou? Você acha que mudou alguma coisa? O que mudou?

Entrevistada: Ah mudou porque se eu ficá em casa, cê vai preocupa com casa, com filhos, entendeu? Talvez a mesma coisa da pessoa que não teve muito estudo, muito deles tem medo de voltá, muitos deles não voltem pra escola porque que existe esta escola, entendeu? Meu caso mesmo, eu morei aqui, tô morando aqui doze anos já, quase na época eu não sabia que existia. Fiquei sabendo pela uma colega minha que trabalha num posto de saúde, entendeu? Daí eu vim pra cá. Mudo bastante viu? Muito...Muito...

Entrevistadora: Por exemplo?

Entrevistada: Prá pegá circular, ajudo bastante porque você vê o nome do circular, entendeu? Porque cê que não tem muito estudo você fica com medo, entende? Eu vou pegar circular errado, vô pro bairro errado, entendeu? E você sabendo cê, entende? Porque por mais assim que tenha dificuldade, porque todo mundo tem dificuldade, entendeu? Até quem estuda, tem um monte de diploma, ele tem dificuldade na vida, entendeu?

No recorte 2, ao perguntarmos, para o sujeito-aluno, qual o sentido que a EJA está fazendo em sua vida, é-nos dado conhecer a seguinte formação discursiva: "Ah eu acho que sim [...] A h mudou porque se eu ficá em casa, cê vai preocupa com casa, com filhos, entendeu?" Percebe-se uma formação discursiva que indica o desejo de mudança, sobretudo da posição de sujeito-dona-de-casa para a de um sujeito mais atuante e autônomo. Podemos dizer, então, que esse sujeito tenta romper com sua memória discursiva ideológica, a qual preconiza que lugar de mulher é no ambiente doméstico, cuidado dos filhos e de seus afazeres do lar. De acordo com Orlandi, "compreendem fundamentalmente os sujeitos e a situação. Também a memória faz parte da produção 
discursiva. A maneira como memória 'aciona', faz valer que as condições de produção são fundamentais [...]” $(2005$, p. 30$)$.

Ao romper com a barreira da memória discursiva cristalizada, a de que o sujeito mulher deve permanecer no ambiente doméstico e cuidar da casa e dos filhos, esse sujeito desloca-se para posição sujeito-aluno e torna-se capaz de produzir um novo sentido que demonstra essa nova posição no contexto em que vive.

Ao ser questionado sobre as mudanças proporcionadas pela EJA, o sujeito-aluno nos diz: "Mudo bastante viu? Muito... Muito... [...] Prá pegá circular, ajudo bastante porque você vê o nome do circular, entendeu? Porque cê que não tem muito estudo você fica com medo, entendeu? Eu vou pegar circular errado, vô pro bairro errado, entendeu?" Ao percebermos o fragmento "Mudo bastante viu? Muito... Muito...", localizamos nova repetição, que, em termos discursivos, não representa somente uma reprodução, mas uma retomada que sempre traz alguma coisa nova. Como afirmam Guilhaumou e Maldidier (1997), esse novo está em outro lugar, no retorno ao arquivo, o que podemos dizer, memória discursiva ou conjuntura histórico-social, ou seja, esse sujeito em questão está construindo uma nova memória discursiva.

Podemos compreender a fala desse sujeito aluno como sendo uma demonstração de tomada de autonomia, pois, ao citar a possibilidade de tomar um ônibus sem precisar da interferência de outros sujeitos a sua volta, identificamos, nesse sujeito entrevistado, certa satisfação. Ao retornarmos a outras formações discursivas, percebemos que o sujeito-aluno usa a expressão "medo" quando diz: "Porque cê que não tem muito estudo você fica com medo, entendeu? Eu vou pegar circular errado, vô pro bairro errado, entendeu?".

A participante do estudo diz ter medo de tomar o ônibus porque, sentindo-se incapaz de ler qual o destino do veículo e contando com o auxílio de alguém, sente que pode ser conduzida a um lugar ao qual não deseja ir. Paulo Freire (1987) diz que o oprimido é aquele que não tem autonomia de ir e vir por si só, pois pode ser enganado por outrem.

De acordo com Pêcheux (1969 apud GADET; HAK, 1997), discurso é efeito de sentido entre locutores. Ao analisar a fala da entrevista da transcrição 1 podemos perceber esse efeito de sentido quando ela produz seu discurso a respeito do medo, associando-o à falta de estudo. Podemos supor que talvez esse sujeito já tenha passado por situações semelhantes que integram sua memória discursiva e que se materializam em seu discurso atual.

Na sequência, encontramos o seguinte fragmento no recorte 2: "Porque por mais assim que tenha dificuldade, porque todo mundo tem dificuldade, entendeu? Até quem estuda, tem um monte de diploma, ele tem dificuldade na vida, entendeu?". O sujeitoaluno entrevistado demonstra saber que, mesmo adquirindo conhecimento intelectual, ele não ficará ausente das dificuldades próprias do mundo capitalista no qual vivemos. Notamos, nesses dizeres, certa preocupação em se sentir inserida junto aos sujeitos mencionados por ela como sendo sujeitos portadores de diplomas, os quais, em sua visão, também enfrentam dificuldades. 
Esse recorte ajuda-nos a reiterar o pensamento de Orlandi, que aponta que o "importante é fazer a escola ir para a rua" (2004, p. 152). Os conhecimentos partilhados no âmbito escolar devem ter sintonia direta com o cotidiano do aluno da EJA.

\section{A fala e a escrita}

Analisaremos, a seguir, um exercício do livro "É bom aprender" que estimula o uso da linguagem oral atrelado à produção escrita.

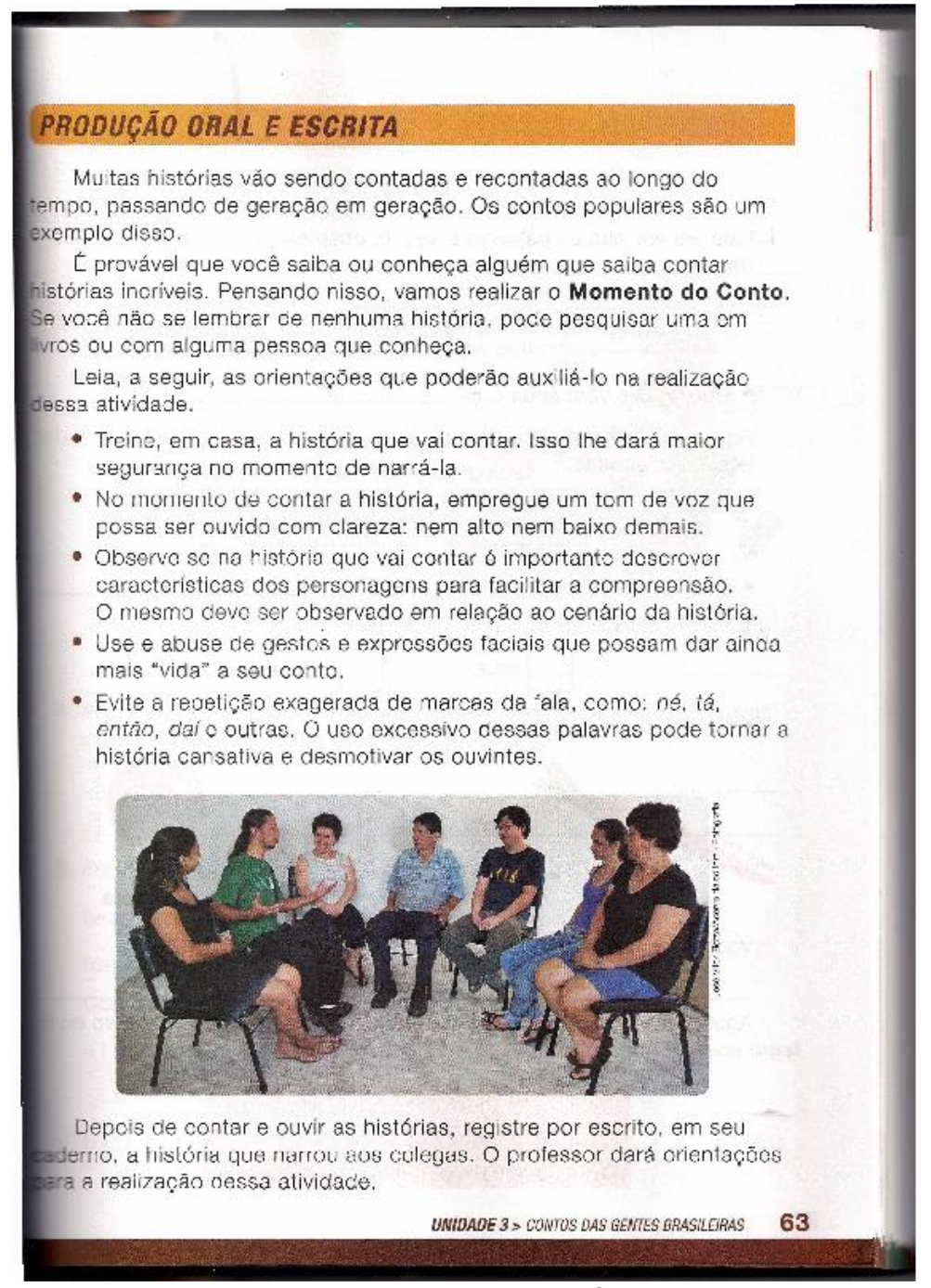

Imagem 04 - Exercício: Produção Oral e Escrita.

No exercício da página 63, defrontamo-nos com uma atividade que prioriza a oralidade e a escrita. No início do capítulo em que se encontra o exercício acima, está incluso um conto referente a Pedro Malasartes, personagem fictício que sempre quer "tirar vantagens" de todas as situações. O exercício em análise vincula-se a esse conto. 
Primeiramente, busca-se saber, do sujeito-aluno, se ele conhece ou não alguém que conte histórias. A atividade não requer que o sujeito-aluno somente redija uma história, mas que a conte, a interprete e a expresse. Para que o exercício seja realizado em sala de aula, o último tópico apresentado orienta: "Evite a repetição exagerada de marcas da fala, como: né, tá, então, daí e outras".

O aluno partilhará oralmente o conto que escolheu, porém não o contará de forma livre. Identificamos aqui a necessidade de se construir uma linguagem moldada pelo padrão correto. Tal exercício, por meio do qual a oralidade é trabalhada de modo evidente, produz o sentido de normatizar a linguagem dos alunos: "Evite [...] né, tá, então, daí e outras".

O moldar da linguagem do estudante é apenas um dos aspectos que configura a educação, pois vemos a escola como "um dos lugares [...] em que a forma-sujeitohistórica que é a nossa (capitalista, de um sujeito com direitos e deveres) se configura como forma sujeito urbana: o adulto letrado, cristão, é urbano como projeto" (ORLANDI, 2004, p. 152).

A aquisição da linguagem padrão se faz pelo processo regido por limitações e recomendações: "Evite". O sujeito-aluno se significa como não analfabeto mediante o uso da escrita. Assim, seu uso no interior da escola e sua linguagem devem ser reformulados para corresponder às exigências da sociedade ou mesmo para que possa ser ouvido ao reclamar seus direitos e cumprir seus deveres. Vemos também que o uso desses termos na fala, no interior do espaço escolar, indica vícios de linguagem e o seu não uso justifica-se como possibilidade de "tornar a história cansativa e desmotivar os ouvintes".

Percebe-se uma preocupação em trabalhar a oralidade da forma dita correta e, a partir dessa mesma perspectiva, podemos examinar a narrativa abaixo, que contempla a questão da fala da contribuição do ensino da linguagem na EJA para a sua vida cotidiana.

Recorte 3:

Entrevistadora: Com o que você espera que a EJA contribua na sua vida?

Entrevistada: Ah eu acho que é uma coisa que vai servi pra mim pro resto da vida, né? Porque o estudo serve pro resto da vida, né? Pra arrumar trabalho, entendeu? Sei lá. Pra você aprende a falar melhor. Então muita coisa, cê convive com as pessoas, né? Conversa, porque primeiro eu não talvez não vou conversar como tô conversando com você hoje, eu tinha mais dificuldade, entendeu? Talvez hoje não, talvez você fica aberta pra conversar, pra falar alguma coisa entendeu? Ajuda bastante. É ajuda bastante.

Ao analisarmos, no recorte 3 , a resposta que nossa entrevistada apresentou ao nosso questionamento, notamos sua preocupação com a trajetória de sua vida, quando comenta: "Ah eu acho que é uma coisa que vai servi pra mim pro resto da vida, né? Porque o estudo serve pro resto da vida, né?" Percebemos, nesse momento, uma 
formação discursiva, a partir da qual o sujeito demonstra certa insegurança quando fala e reforça a afirmação com uma pergunta para a entrevistadora. Podemos compreendê-la como sendo uma afirmação já ouvida pelo sujeito, mas nem sempre entendida. Neste momento, podemos nos aportar em Orlandi (2005), que nos ensina que "todo discurso se delineia na relação com os outros: dizeres presentes e dizeres que se alojam na memória" (p. 43).

O sujeito, neste caso, já tinha ouvido falar antes que o estudo serve para toda vida e essa concepção ficou guardada em sua memória, espaço dos efeitos da lembrança e do esquecimento, das repetições, das redefinições, das rupturas e das transformações em um dado processo discursivo (PFEIFFER, 1995).

Somos capazes de indicar ainda que houve uma formulação de sentido quando o sujeito, segundo ele mesmo, projetou esse conhecimento adquirido na EJA para o resto de sua vida. Como nos diz Orlandi (2008), na Análise do Discurso, o sujeito é posição entre outras e subjetiva-se na medida mesmo em que projeta sua situação, ou seja, seu lugar no mundo para sua posição no discurso.

Em outro fragmento da formação discursiva do sujeito acima, observamos a preocupação em se manter no mercado de trabalho. Essa preocupação torna-se evidente quando comenta que o estudo servirá para que possa conseguir um emprego. "Pra arrumar trabalho, entendeu?" Podemos notar que, para a entrevistada, a educação também é uma forma de preparação para que ela possa se inserir no mercado de trabalho. Expressa-se aí a perspectiva ideológica do sistema capitalista no qual vivemos, no qual o sujeito imagina-se mais valorizado pelo fato de estar produzindo. Vale indicar também que esse produzir não se constitui somente no fato mecânico da produção em si, mas sim como forma de ruptura, de independência desse sujeito, que, ao ser produtivo, terá como resultado uma maior independência financeira, a qual possibilitará um deslocamento social.

Como afirmamos, existe, nesse fragmento, uma preocupação - reconhecida como natural devido à própria idade da entrevistada - em se preparar melhor para continuar no mercado de trabalho, porém em melhores condições, ou seja, na condição de sujeito letrado.

Encontramos, na sequência da entrevista, outra formação discursiva: "Sei lá. Pra você aprende a falar melhor. Então muita coisa, cê convive com as pessoas, né? Conversa". Ao analisarmos esse discurso, devemos considerar um sujeito que está buscando algo melhor para sua vida, que está tentando entrar em um mundo do qual acha que não faz parte. Para a entrevistada, o mundo dos que tiveram estudo é completamente diferente do mundo em que ela se sente inserida. Orlandi (2008) nos ajuda a compreender essa situação ao afirmar que "o sujeito, na Análise de Discurso, é posição entre outras, subjetivando-se na medida mesmo em que se projeta de sua situação (lugar) no mundo para sua posição no discurso" (p. 99).

Em outra sequência discursiva, a entrevistada relata: "porque primeiro eu não talvez não vou conversar como tô conversando com você hoje, eu tinha mais dificuldade, entendeu? Talvez hoje não, talvez você fica aberta pra conversar, pra falar alguma coisa entendeu? Ajuda bastante. É ajuda bastante." Compreendemos, nesse discurso, que esse 
sujeito-aluno da EJA já está se sentindo em uma situação privilegiada, pois quando diz "talvez não vou conversar como tô conversando você hoje, eu tinha mais dificuldade, entendeu?", coloca-se em uma outra posição em que antes não se via, ou seja, ela se diz agora mais capaz de conversar com as pessoas. Parafraseando Orlandi (2008), devemos nos lembrar de que sujeito e sentido constituem-se ao mesmo tempo, ou seja, na tensão da língua com a história, onde entram o imaginário e a ideologia. Percebe-se $\mathrm{o}$ deslocamento e o uso da memória discursiva. Ela se vê antes e, agora, na EJA.

O papel da memória histórica seria, então, o de fixar um sentido sobre os demais (também possíveis) em uma dada conjuntura. Ou ainda, vista deste ângulo, "à memória estaria reservado o espaço da organização, da linearidade entre o passado, presente e futuro, isto é, a manutenção de uma coerência interna da diacronia de uma formação social" (MARIANI, 1993 apud PFEIFFER, 1995, p. 25)

Aqui se nota que o sujeito-aluno em questão retoma a sua memória quando nos diz que talvez, anteriormente, ela não se sentisse em condições de dialogar com pessoas vistas como superiores a ela. Compreendemos que a entrevistada já se percebe em uma situação mais privilegiada, ou seja, ela já se significa como sendo uma pessoa capaz de conversar em igualdade de condição. Ao retornar a sua memória histórica, ela fixa um sentido novo numa nova conjuntura.

\section{Algumas considerações finais}

A questão da Educação de Jovens e Adultos (EJA) aproxima-nos de várias dimensões como a política, a social e a cultural, dentre outras. Embasados na problemática educacional da atualidade, buscamos compreender a complexidade do contexto vinculado à formação de aluno da EJA, questionando-nos: quais são os sentidos que a formação da EJA produz para esses sujeitos?

$\mathrm{O}$ uso do livro didático adequado à sua linguagem e às suas experiências integra a formação do aluno da EJA. Compreendemos a constituição desse material formulado com uma linguagem que produz sentidos aos alunos (jovens e adultos) que dele fazem uso, significando-o e se significando. O livro analisado apresenta algumas situações que contribuem de modo prático na vida do aluno, propiciando, dessa forma, a formação de um aluno que sirva aos interesses do Estado.

A partir das análises das falas do sujeito-aluno - aprendiz da EJA -, foi possível tecer alguns sentidos sobre a singularidade do sujeito, que, em seus discursos, transmite desejos e contradições ao se ver inserido em um sistema educacional. Os exames realizados nos possibilitaram entender e perceber que, de "um lado há imprevisibilidade na relação do sujeito com o sentido da linguagem com o mundo" e que "toda formação social, no entanto, tem formas de controle da interpretação, que são historicamente determinadas" (ORLANDI, 2005, p. 10). 
Este artigo é apenas um olhar, pautado em uma problematização dos sentidos dos sujeitos-alunos da EJA, e corresponde a um contexto de discussão de questões atuais da educação brasileira.

\section{Referências bibliográficas}

BITTENCOURT, C. M. F. Ensino de História: fundamentos e métodos. São Paulo: Cortez, 2004.

BRASIL. Ministério da Educação. Fundo Nacional de Desenvolvimento da Educação. Conselho Deliberativo. Resolução nº 51 de 16 de setembro de 2009. Disponível em http://portal.mec.gov.br/index.php?option=com_docman\&task=doc_download\&gid=10 026\&Itemid=; acesso em set. de 2013.

BRASIL. Lei de Diretrizes e Bases da Educação Nacional, Lei no 9394, de 20 de dezembro de 1996. Disponível em www.mec.gov.br; acesso em ago. 2012.

CAVAlCANTI, R. A. Andragogia: a aprendizagem nos adultos. Revista de Clínica Cirúrgica da Paraíba, n. 6, ano 4, jul. 1999.

DI PIERRO, M. C.; JOIA, O.; RIBEIRO, V. M. Visões da educação de jovens e adultos no Brasil. Caderno Cedes, Campinas, SP, ano XXI, nº. 55, novembro 2001.

FLECHA GARCIA, R. Efeito desnivelador y educación comunicativa. In: Educación de jovens y personas adultas em España. Barcelona: Crea, 1996.

FREIRE, P. Pedagogia da autonomia: saberes necessários à prática educativa. São Paulo: Paz e Terra, 1996.

Pedagogia do oprimido. 17a . ed. Rio de Janeiro: Paz e Terra, 1987.

GADET, F; HAK, T. (Org.) Por uma análise automática do discurso: uma introdução à obra de Michel Pêcheux. Trad. Bras. 3 ${ }^{\text {a }}$ ed. Campinas, SP: Editora da Unicamp, 1997.

HADDAD, S. Tendências atuais na educação de jovens e adultos. Em Aberto, Brasília, out./dez., vol. 11, no 4, 1992.

MALDIDIER, D. Discurso e ideologia: bases para uma pesquisa. Em: ORLANDI, E. (Org.). Gestos de leitura: da história no discurso. Campinas, SP: Ed. da Unicamp, 1997.

ORLANDI, Eni. Discurso e Texto: formulação e circulação dos sentidos. $3^{\text {a }}$. ed. Campinas, SP: Pontes Editores, 2008.

Análise de discurso: Princípios e Procedimentos. Campinas, SP: Pontes, $6^{\circ}$ edição, 2005. 
Cidade dos sentidos. Campinas, SP: Pontes, 2004.

Interpretação: autoria, leitura e efeitos do trabalho simbólico. $4^{\mathrm{a}}$. ed. Campinas: Pontes, 2004.

A linguagem e seu funcionamento: as formas do discurso. $4^{\mathrm{a}}$ ed. Campinas, SP: Pontes, 2003.

PÊCHEUX, M. Análise automática do discurso (AAD 69). Em: GADET, F.; HAK, T. Por uma análise automática do discurso: uma introdução a obra de Michel Pêcheux. Trad. Bras. $3^{a}$. ed. Campinas, SP: Editora da Unicamp, 1997.

O discurso: estrutura ou acontecimento. Trad. Bras. Campinas, SP: Pontes, 1990. [1975] Semântica e discurso: uma crítica à afirmação do obvio. Trad. Bras. 2a. ed. Campinas, SP: Editora da Unicamp, 1997.

PFEIFFER, C. R. C. Que autor é este? Dissertação. Mestrado em Linguística. Universidade Estadual de Campinas, Campinas, 1995.

Para citar este texto:

DOMINGUES, Andrea Silva; LARAIA, Marilda de Castro. $O$ discurso fundador e a educação de jovens e adultos: um movimento social necessário no Brasil. Entremeios [Revista de Estudos do Discurso], Seção Estudos, Programa de Pós-graduação em Ciências da Linguagem (PPGCL), Universidade do Vale do Sapucaí, Pouso Alegre (MG), vol. 12, p. 93-113, jan. - jun. 2016.

DOI: http://dx.doi.org/10.20337/ISSN2179-3514revistaENTREMEIOSvol12pagina93a113 